\title{
ORÁN Y ARGEL EN LA OBRA DE CERVANTES
}

\author{
Reda Abi Ayad \\ Universidad de Orán
}

\begin{abstract}
Resumen
Orán y Argel, son dos ciudades de Argelia que marcaron la vida y obra de Miguel de Cervantes. Por un lado, Orán, presidio español en el norte de África desde I509 a I792; y por otro, Argel, ciudad corsaria y lugar de detención de los cautivos cristianos hechos presos en el Mediterráneo. El cautiverio de Cervantes en Argel entre 1575 y I580 le permitió conocer perfectamente la ciudad, al igual que la cultura arabomusulmana, para luego ponerla en escena a través de sus obras de cautiverio: Los baños de Argel, El trato de Argel e incluso La historia de cautivo incluida en el Quijote, sin olvidar el episodio de los falsos cautivos insertado en el Persiles. Orán para los cautivos simbolizaba la puerta de salida y la libertad antes de alcanzar España. Razón por la cual, Cervantes debió de interesarse por esta ciudad para poder fugarse desde Argel hacia Orán. Además, su visita en Orán en 158I le permitió observar la situación de los soldados españoles que luchaban por la Corona española en territorio argelino, lo que va a reflejar más tarde a través de su comedia El Gallardo español. Toda esta influencia aparecerá a lo largo de la producción literaria de Cervantes, referencias que trataremos a través de este artículo.
\end{abstract}

Palabras clave: Cervantes, cautiverio, Argel, Orán, referencia autobiográfica, influencia.

\begin{abstract}
Oran and Algiers, the two Algerian cities, had a great influence over the life and the works of Miguel de Cervantes. In one side, Oran placed under the Spanish colonization from I509 to I792; in the other side, Algiers, a corsair city and a place of imprisonment for the Christian captives taken in the Mediterranean Sea. Captivated in Algiers from 1575 to I580, Cervantes gained a great knowledge of the city and the Arab Muslim culture, and utilized that eventually in his literary works: Los baños de Argel, El trato de Argel even "The Captive's Story" included in Don Quixote, and the episode of the false captives inserted in Persiles. Oran for the captives symbolized the exit door to freedom before reaching Spain that's the reason why, Cervantes had to be interested in this city as his intentions were to escape from Algiers. Furthermore, his visit to Oran in $158 \mathrm{r}$ allowed him to observe the situation of the Spanish soldiers who were fighting for the Spanish Crown in the Algerian territory, which he later reflected through his comedy El Gallardo español. Thus, all this influence will appear throughout the literary works and references of Cervantes that we will deal with throughout this article.
\end{abstract}

Keywords: Cervantes, captivity, Algiers, Oran, autobiographical reference, influence. 


\section{INTRODUCCIÓN}

Orán y Argel en la Época moderna eran dos ciudades pertenecientes al reino de Tremecén, cuya actividad comercial se extendía por todo el Mediterráneo. A principios del s. Xvi, Orán y Argel se encuentran políticamente divididas; por un lado, Orán, bajo el gobierno español de los Alcaudete; y por otro Argel, que estaba bajo dominio otomano. La literatura española ha tratado abundantemente ambas ciudades, pero encima de todos los autores que las han descrito, sobresale la figura de Miguel de Cervantes, vinculado irremediablemente con las ciudades argelinas. Ya sea en el Quijote (1605-I615), en El trato de Argel (1582), en Los baños de Argel (I6I5) o El gallardo español (I6I5), Cervantes evoca con reminiscencia su cautiverio en Argel (I575-I580), pero también el asedio de Orán y la situación dramática de los soldados españoles en Orán durante el asedio de 1563 , tras su visita en Orán en 1581, la batalla de Mazaghran de 1558 e incluso la presencia de los moriscos en España durante su época.

\section{OrÁn En EL TRATO DE ARGEL}

Durante su cautiverio en Argel, Cervantes tenía ya bastantes conocimientos sobre las plazas españolas de Orán y su topografía ${ }^{1}$. Su plan era evadirse de Argel hacia Orán y gozar, así, de la libertad que tanto anhelaba. Se hace referencia en la estrofa siguiente, a los ríos, los montes y sierras, al igual que a los árabes que vivían en el campo, tal como lo expresa en El trato de Argel, a través de este diálogo que alude a la fuga:

-Pues ¿cómo piensa ir?

-Qué agora, como es tiempo de verano,

Los alárabes todos a la sierra,

Se retiran, buscando el fresco viento

— ¿llevas algunas señas por do entiendas

Cuál es de Orán la deseada tierra?

- Sí llevo, y sé que he de pasar primero

Dos ríos: uno del bates, nombrado, río del azafrán, que está aquí junto;

otro, el de Hiqueznaque, que es el más lejos.

1 Cf. María Antonia Garcés, Cervantes en Argel, historia de un cautivo, Madrid, Gredos, 2005. 
Cerca de Mostagan ${ }^{2}$, y a mano derecha, está una levantada y grande cuesta, que dicen que se llama el cerdo Gordo, y puesto encima de ella se descubre frente por frente un monte, que es la silla que sobre Orán levanta la cabeza ${ }^{3}$.

Como se nota en este fragmento, Cervantes tenía bastantes conocimientos topográficos sobre Orán y su alrededor, también conocía la ciudad de Mostaganem, muy anhelada por los españoles en su época.

\section{OrÁn en EL GALLARDO ESPAÑOL}

Cervantes dedica toda una comedia a la ciudad de Orán, la de El gallardo español. En efecto, las acciones de la pieza se desarrollan en Orán y Mazalquivir, precisamente en la época del gobierno de la familia de los Alcaudetes, donde hubo el terrible asedio de Orán y su puerto por Hassan Pacha en 1563, para intentar liberar los dos enclaves de la presencia española.

Durante el enfrentamiento entre las dos comunidades, cristiana y musulmana, el protagonista y héroe Ali Muzel interpela y desafía al gallardo español, don Fernando, capitán del ejército español, delante de la puerta Canastel de Orán, de este modo:

Y así, a ti te desafío,

Don Fernando el fuerte, el bravo,

Tan infamia de los moros [...]

Aquí, junto a Canastel,

Solo te estaré esperando

Hasta que mañana el sol

Llegue al poniente su carro ${ }^{4}$.

2 Mostagán o Mostaganem, una ciudad en el este de Orán conocida por los españoles por la batalla de Mazagrán, que enfrentó en 1558 a españoles y argelinos, y que terminó con la muerte del conde de Alcaudete, Gobernador de Orán (1534-1558).

3 Miguel de Cervantes, El trato de Argel, edición publicada por Rodolfo Schevill y Adolfo Bonita, Biblioteca virtual Miguel de Cervantes, Universidad de Alicante, 2003, p. 64.

4 Miguel de Cervantes, El gallardo español, Madrid, Espasa-Calpe, 1970, p. 78. 
Del mismo modo, se puede observar también la bravura de Ali Muzel, que Cervantes resalta de esta manera:

Escuchad los de Orán,

Caballeros y soldados

Que firmáis con nuestra sangre

Vuestras luchas señaladas.

Buitrago, otro personaje de la comedia, nos describe el asedio y la confrontación militar entre españoles y moros de esta manera:

¡Arma, arma, señor, con toda priesa,

Porque en el charco azul columbro y veo

Pintados leños de una armada gruesa

Hacer un círculo y rodeo! ${ }^{5}$

Los soldados españoles en Orán vivían constantemente ataques por parte de los oraneses, que querían liberarse del invasor español. Para lograrlo, los oraneses acudían a algunas estrategias, entre otras, asediar a los españoles en Orán para impedir la llegada de los vivires y del abastecimiento militar por el mar, con el fin de debilitarles y obligarles a retirarse.

\section{ORÁN EN LAS NOVELAS EJEMPLARES: LA GITANILLA}

Mis investigaciones sobre las Novelas ejemplares me llevaron principalmente a la Gitanilla, en la que se hacen alusiones sobre Orán, a través de la protagonista. Aquí, la imagen y representación del personaje de la Gitanilla — que se caracteriza por la magnificencia, el cariño y la belleza ideal- Cervantes la simboliza a una paloma y leona de Orán:

Hermosita, hermosita, La de las manos de plata,

Más te quiere tu marido

Que el Rey de las Alpujarras.

Eres paloma sin hiel;

Pero a veces brava 
Como leona de Orán,

O como tigre de Ocaña ${ }^{6}$.

Aparece también en este fragmento una alusión a la región de las Alpujarras, famosa por los moriscos que vivían cerca en Granada, y que se sublevaron contra Felipe II y su política de represión religiosa.

\section{OrÁn en el Quijote}

Cervantes no deja de referirse a la ciudad de Orán en sus obras. Al igual que otras ciudades, Toledo, Florencia, Nápoles, etc., Orán está presente y ocupa un lugar privilegiado, puesto que ha marcado considerablemente su espíritu narrativo y personal ${ }^{7}$. En la primera parte del Quijote, en el episodio del cautivo, inicia su cuento situándonos en un lugar llamado Montañas de león, aludiendo seguramente a Orán por su valor implícito y simbólico:

En un lugar de las montañas de león, tuvo principio mi linaje, con quien fue más agradecida y liberal la naturaleza que la forma aunque en la estrecheza de aquellos pueblos todavía alcanzaba mi padre fama de rico ${ }^{8}$.

Luego más tarde, en la segunda parte del Quijote, Cervantes evoca otra vez Orán y sus famosos leones, que el Gobernador de Orán regaló al Rey de España. En el diálogo entre el carretero y don Quijote se lee lo siguiente:

— ¿Adónde vais, hermano? ¿qué carro es éste, qué llevas en él y qué banderas son aquéstas?

-El carro es mío; lo que va en él son dos bravos leones enjaulados, que el general de Orán envía a la corte, presentados a su Magestad; las banderas son del rey nuestro señor, en señal que aquí va cosa suya ${ }^{9}$.

6 Miguel de Cervantes, La gitanilla, edición de Juan Bautista Avalle Arce, Madrid, Castalia, 1982, p. 93.

7 Véase el artículo de A. Abi Ayad: "Orán: fuente literaria y lugar de escritura de Miguel de Cervantes”, en María Cruz García de Enterría y Alicia Cordón Mesa (eds), Actas del IV Congreso Internacional de la Asociación Internacional Siglo de Oro (AISO), Alcalá de Henares, Universidad de Alcalá, 1998, pp. 117-126.

8 Miguel de Cervantes, Don Quijote de la Mancha, textos y notas de Martín de Riquer, Barcelona, Juventud, 1968, vol. I, cap. XXXIX, p. 395.

9 Ibid., vol. II, cap. XVI, p. 654. 
Orán en las creencias populares está simbolizada por dos leones grandes, representativos de la presencia de los leones en aquella época, lo que no escapó a los oídos de Cervantes, muy atento a lo que se decía acerca de la ciudad en su época.

\section{Orán en el Persiles}

Cervantes no deja de aludir a su pasado de cautivo en Argel y la privación de libertad e incluso en su última obra el Persiles donde alude a través del narrador a su tentativa de evasión y tránsito por Orán, de este modo:

Las galeras - respondió el cautivo- eran de don Sancho de Leyva; la libertad no la conseguimos, porque no nos alcanzaron; tuvimosla después, porque nos alzamos con una galeota que desde Sargel iba a Argel cargada de trigo; venimos a Orán con ella, y desde allí a Málaga, de donde mi compañero y yo nos pusimos en camino de Italia, con intención de seguir a su Majestad, que Dios guarde, en el ejercicio de la guerra ${ }^{10}$.

Esta evocación de Orán denota el impacto de su estancia en dicha ciudad hasta finales de su vida ${ }^{11}$. Cervantes hace referencia también al intercambio mercantil entre Orán y Málaga, muy famosa en la época por su trigo.

\section{Argel en EL trato de ARGEL}

Tras su liberación de Argel, Cervantes empieza su nueva carrera literaria escribiendo su primera comedia, El trato de Argel, donde pone en escena la ciudad de Argel ${ }^{12}$ y su cautiverio allá: “... gomia y tarasca de todas las riberas del mar Mediterráneo, puerto universal de corsarios, y amparo y refugio de ladrones":

10 Miguel de Cervantes, Los trabajos de Persiles y Sigismunda, edición virtual publicada por Rodolfo Schevill y Adolfo Bonilla, Biblioteca Virtual Miguel de Cervantes, Universidad de Alicante, Cap. X.

11 Véase mi artículo "E1 Persiles: Síntesis del pensamiento literario de Miguel de Cervantes", en Ismet Terki Hassaine, José E. Sola Castaño, Alejandro Ramón Díez Torre, y Manuel Casado Arboniés (eds.), Las campanas de Orán, 1509-2009: Estudios en homenaje a Fatma Benhamamouche, Alcalá de Henares, Universidad de Alcalá, 2012, pp. 377-386

12 Véase el artículo de A. Abi Ayad: "Argel: una etapa decisiva en la obra y pensamiento de Cervantes”, en Actas del II Congreso Internacional de la Asociación de Cervantistas. Nápoles, Sociedad Editrice Gallo, 1995, pp. 133-142. 
¡Triste y miserable estado!

¡Triste esclavitud amarga,

Donde es la pena más larga

Cuán corto el bien y abreviado

¡Oh purgatorio en la vida,

Infierno puesto en el mundo,

Mal que no tiene segundo,

Estrecho do no hay salida! ${ }^{13}$

Argel en el s. XVI se conocía por la actividad corsaria en el Mediterráneo, que frenaba considerablemente el comercio marítimo español. Muchos cristianos españoles se hicieron presos por los corsarios otomanos, que les usaban de esclavos para los trabajos de interés público, o como moneda de cambio para negociar asuntos diplomáticos ${ }^{14}$.

VII. Argel en LoS baños de ARGEL

Los baños de Argel es otra obra en la que Cervantes se dedica al tema del cautiverio y a los cautivos españoles en los baños de Argel. Como lo expresa el escritor de Alcalá, Argel tenía un lugar preponderante en el Mediterráneo en cuanto al comercio, y era una ciudad muy cosmopolita, donde se mezclaban muchas religiones:

Argel es, según barrunto

Arca de Noe abreviada, Aquí están de todas suertes.

$Y$ aun otra cosa, si adviertes,

Que es de más admiración, $\mathrm{Y}$ es que estos perros sin fe

Nos dejen como se ve

Guardar nuestra religión

que digamos nuestra misa

Nos dejan, aunque en secreto ${ }^{15}$.

13 Miguel de Cervantes, El trato de Argel, loc. cit., p. 1.

14 Véase artículo de Maximiliano Barrio Gonzalo, (2003): "Los cautivos españoles en Argel durante el siglo ilustrado”, en Cuadernos dieciochistas, 2003, vol. 4, pp. 135-174.

15 Miguel de Cervantes, Los baños de Argel, edición de Jean Canavaggio, Madrid, Taurus, 1984, pp. 123-129. 
Cervantes se refiere también a la libertad que podían tener ciertos cautivos según su rango social y el valor estimado por sus amos:

Pues amigo? Adónde vamos?

Aunque está de aquí un buen rato

Al jardín de Agimorato.

Allí podremos asolas

Danzar, cantar y tañer

$Y$ hacer nuestras cabriolas.

Demos vado a la pasión,

Cuanto más, que es la intención

Del cadi que nos holguemos

$\mathrm{Y}$ que los viernes tenemos

Honesta recreación ${ }^{16}$.

Encontramos también un magnífico romance sobre el mar y la libertad que simboliza por los cautivos españoles:
A las orillas del mar
Con su lengua y sus aguas,
Ya manso, ya airado, llega
Del puerto de Argel las murallas
Con los ojos del deseo
Están mirando a su patria
Cuatro míseros cautivos
Que del trabajo descansan,
$\mathrm{Y}$ al son de ir y volver
De las olas en la playa,
Con desmayados acentos
Esto lloran y esto cantan:
¡cuán cara eres de haber,
Oh dulce España! ${ }^{17}$

Aparece con frecuencia la noción de libertad frente a la situación vivida por los cautivos: 
Es gran el gusto que encierra

Voz de libertad.

Siempre huir por tierras aspiras

Tres veces por tierra has huido ${ }^{18}$.

\section{Argel en el QuiJote}

Cervantes dedica todo un capítulo al cautiverio a través de la Historia del cautivo. Esa historia es una historia independiente dentro de la historia general. El episodio viene justo después de un debate muy profundo entre don Quijote y Sancho Panza, sobre "las armas y las letras". Los tres capítulos nos cuentan la historia de un soldado español hecho preso en Argel y la historia de amor que va a tener con Zoraida, una rica y preciosa mora de la ciudad.

La historia empieza de la manera siguiente: un padre bastante rico y preocupado por el porvenir de sus tres hijos, decide repartir sus bienes y orienta la carrera de sus hijos hacia lo siguiente: "iglesia o mar o casa real", es decir: "quien quisiera valer y ser rico, siga o la Iglesia o navegue, ejerciendo el arte de la mercancía, o entre a servir los reyes en sus casas", o en otras palabras: "que uno de vosotros siguiese las letras, el otro la mercancía, y el otro siguiese al rey en la guerra" (letras, armas o comercio).

Cervantes nos narra con eso algunas creencias socioculturales de su época, respecto a cómo se puede lograr el éxito económico y social en aquel entonces. Ese acontecimiento nos hace pensar en el mismo acontecimiento histórico que vivió el propio Cervantes, al haber estado cinco años cautivos en Argel (I575-I580), tras la famosa batalla de Lepanto en I57I.

Esta historia pertinente, sin embargo, independiente de la historia general de la novela, figura en la primera parte del Quijote, precisamente en los capítulos XXXIX, XL y xLI. Nos relata los años de cautividad del ilustre autor y soldado español, hecho cautivo durante cinco años en Argel por los otomanos, a través del héroe de su historia.

El protagonista de esta historia, miembro de la familia de Pérez de Viedma, se hace cautivo en los baños de Argel. Gracias a la ayuda de Zoraida, una mora convertida al cristianismo llamándose María, el joven soldado junto a otro cautivo renegado cautivado con él, llega a evadirse

18 Ibid., p. 73. 
de prisión y recuperan su libertad. De allí, empieza una pasión amorosa entre el héroe y la bella mora, a través del amigo renegado que les hacía oficio de intérprete. Al final de una larga correspondencia entre los dos amantes, estos últimos llegan a procurarse un barco y se van juntos hacia España para vivir plenamente su amor.

Hay que señalar que el propio Cervantes no tuvo esa suerte de evadirse cuando estuvo cautivo. En efecto, numerosas tentativas, cinco en total, acabaron en fracaso. Habrá que esperar a que la Orden de la Trinidad de España le rescate, junto a otros cautivos, para que recupere su anhelada libertad.

En esta historia del cautivo, Cervantes alude a un hecho cultural importante en su época, a saber, el matrimonio mixto y los amores cruzados entre moros y cristianos. No se rechaza la hipótesis de que Cervantes haya tenido una aventura amorosa, o por lo menos, haya sido atraído por moras de Argel, durante su cautividad.

A través de su relato, el autor alude también a la época otomana. Evoca pues algunas figuras emblemáticas de su época, tales como los legendarios hermanos Barbarroja, o bien Uluç Ali, el capitán italiano encargado de la Regencia de Argel a finales del s. Xvi. Nos cuenta también el tratamiento de los cristianos cautivos en Argel por los otomanos.

Según Cervantes, había dos tipos de cautivos en Argel: los cautivos destinados a ser rescatados, que se encerraban en una prisión llamada baño; y otros, a los que llamaban de almacén, que servían a la ciudad en las obras públicas. El cautivo de esa historia, que pertenecía a los cautivos de rescate, nos describe su cautividad de esa manera:

Pusiéronme una cadena, mas por señal de rescate que por guardarme con ella, y así pasaba la vida en aquel baño, con otros muchos caballeros y gente principal, señalados y tenidos por de rescate ${ }^{19}$.

A través de esto, entendemos que el cautivo no estaba solo en los baños y que había otros cautivos en espera de rescate. También nos enteramos de que había cierta suavidad en cuanto al trato de los cautivos, a pesar de las cadenas puestas en sus manos. 


\section{Argel en el Persiles}

Cervantes dedica todo un capítulo en su última obra el Persiles a Argel, a través del episodio de los falsos cautivos. Este episodio picaresco pone en escena dos jóvenes mozos, vestidos de un traje de cautivos y que pretenden contar la historia de su supuesta desgracia a cambio de dinero. Un lienzo pintado les sirve de soporte a su falso relato, con el fin de gustar y entusiasmar a un público con afán de novedades.

A través de este episodio, Cervantes recurre a su memoria y a su pasado de cautivo en Argel para hacernos una descripción sobre la ciudad y sus puertas, también evoca su situación económica vista por él. Trata también el asunto de los cautivos españoles durante la Regencia de Argel, con el fenómeno del corso y de la piratería en todo el Mediterráneo:

Esta, señores, que aquí veis pintada, es la ciudad de Argel, gomia y tarasca de todas las riberas del mar Mediterráneo, puerto universal de corsarios y amparo y refugio de ladrones, que, deste pequeñuelo puerto que aquí va pintado, salen con sus bajeles a inquietar el mundo, pues se atreven a pasar en plus ultra de las columnas de Hércules, y a acometer y a robarlas apartadas islas que, por estar rodeadas del inmenso mar Océano, pensaban estar seguras, a lo menos de los bajeles turquescos ${ }^{20}$.

En el mismo diálogo entre los dos pícaros, Cervantes menciona algunas ciudades argelinas, tales como Argel, Cherchel y Orán, según el texto que hemos visto anteriormente ${ }^{21}$.

\section{Conclusión}

Para concluir, Cervantes se inspira en su propia experiencia de cautiverio en Argel y su visita a Orán para introducir en sus relatos acontecimientos históricos y ciudades reales, siendo fuente de la dimensión real, histórica y literaria de las ciudades argelinas. Todas estas referencias sobre Orán y Argel demuestran la influencia y el impacto que tuvieron estas dos ciudades en la vida y obra de Miguel de Cervantes, hasta el punto de reflejarse de manera reiterativa y persistente desde sus textos

20 Miguel de Cervantes, Los trabajos de Persiles y Sigismunda, op. cit., libro III, cap. 10, p. 531. 21 Vid. supra nota 10. 
58 Reda Abi Ayad

más emblemáticos a su última obra el Persiles, dejándonos huellas y testimonios imborrable en su literatura. 